\title{
LEGIBILITY
}

A major purpose of the Technical Information Center is to provide the broadest dissemination possible of information contained in DOE's Research and Development Reports to business, industry, the academic community, and federal, state and local governments.

Although a small portion of this report is not reproducible, it is being made available to expedite the availability of information on the research discussed herein. 


$\begin{array}{ll}\text { AUTHOA(S) } & \text { A. F. Voter } \\ & \text { S. P. Chen } \\ \text { R. C. Albers } \\ \text { A. M Boring } \\ \text { P. J. Hay }\end{array}$

Sugmited to Proceedings of the 1988 World Materials Congress: Session entitled "Atomist ic Modeling of Materials: Beyond Pair Pocentials"

\section{IDISC I.AIMER}

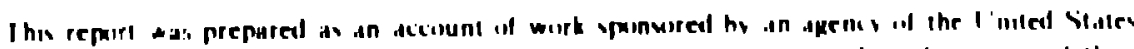

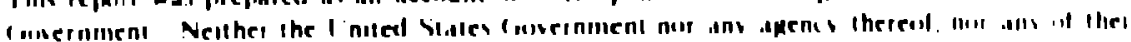

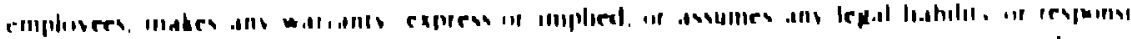

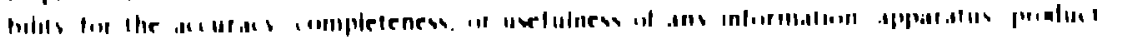

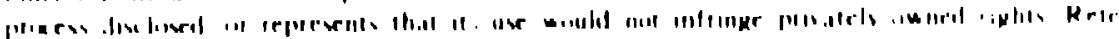

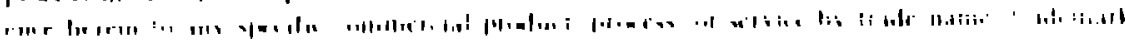

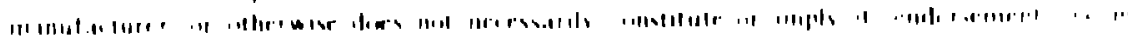

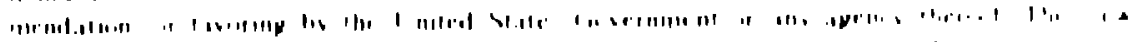

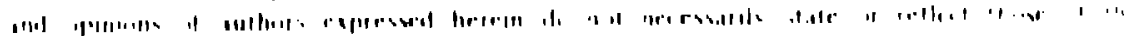

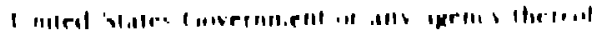

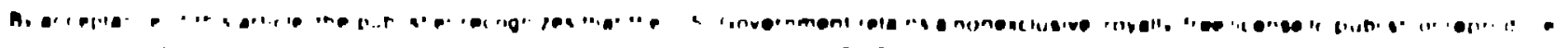

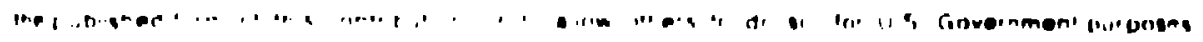

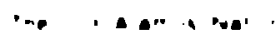




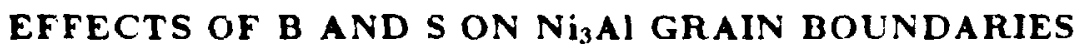

\author{
A. Foter, S P Chen, R C. Albers, A M Boring, and P J Hay \\ Los Alamos National Laboratory \\ Los Alamos, NiM 87545
}

\section{INTRODUCTION}

In many materials, the mechanical behavior is controlled by the grain boundary (GB) properties, An extreme example is the ordered alloy $\mathrm{Ni} / 3 \mathrm{Al}$. which, as a single crystal. is ductile while as a polycrystal. pur." $\mathrm{Ni}_{3} \mathrm{Al}$ exhibits severe intergranular brittleness. making it useless as a technological material. However. It has been found[1] that doping $N_{i g} A$ l that is slightly $N_{i-r i c h}\left(76 \% N_{1}\right)$ with small announts of boron ( 1.2 atome $\%$ ) restores the ductility almost to the level of the single crystal While it us known experminentalls that B segregates to grain boundaries[1], the mechanism hy which ductilization occurs is not knum $n$ ll, present here resuits of our initial investigation into the effects of impurities on $\mathrm{N}_{13} \mathrm{Al}$ gram biundaries. Usiu: interatomic potenuads of the embedded atom[2.3] form. coupled with molecular stalics :echniques

Theoretical studies of grain boundaries in homomuclear systems have been repcrted by many zuthors 1 ; Both molecular staties and noleculas dynamucs te chmmues have been empiloyed As a result of these sturi. the general strurtural features and. to a lexer extent the energetics. of pure element (iBs are nuk unil.

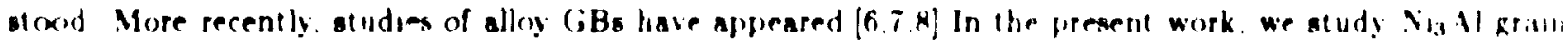

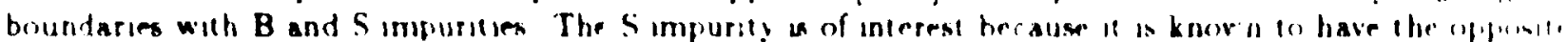
effect from B on GBs it promotes intergranulat fencture

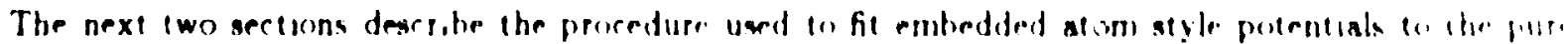

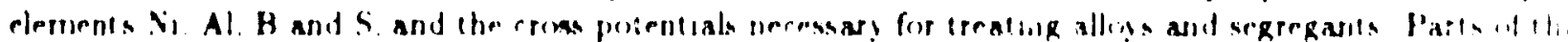

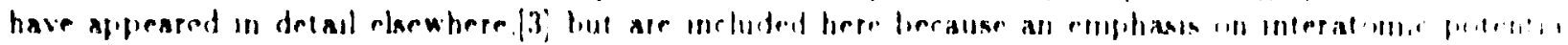

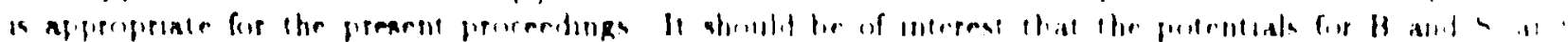

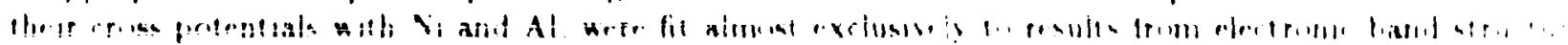

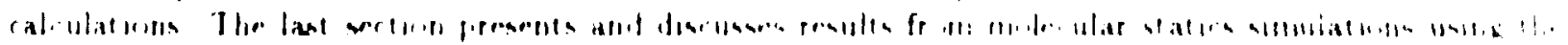
purniliak

\section{INTEIHACTION PQIEATIALS FUIU IVI. AI. B. ANIUS}

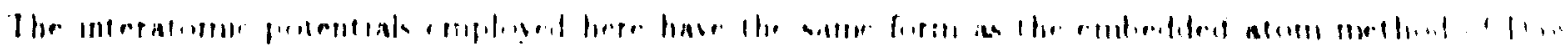

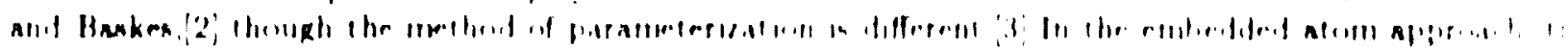

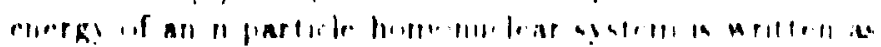

$$
1 \quad 192, \ldots+1, \ldots
$$


where $r_{1}$ is the distance between atoms $i$ and $j . \phi$ is a pairwise interaction potential, $F$ is the embifing function, and $\vec{\rho}_{1}$ is the density at atom, due 10 all its neighbors.

$$
\bar{\rho}_{1}=\sum_{g(\neq 1)}^{n} \rho\left(r_{1}\right)
$$

The pairwise potential is taken to he a Morse potential

$$
\phi(r)=D_{M}\left\{1-\exp \left[-\sigma_{M}\left(r-R_{M}\right)\right]\right\}^{2}-D_{M}
$$

The three parameters, $D_{M}, R_{M}$, and $a_{M}$. define the depth, distance to the minimum, and a measure of $t_{1}$ curvature at the minimum, respectively. The density function, $\rho(r)$, is taken as

$$
\rho(r)=r^{6}\left|e^{-s r}+2^{4} r^{-2 s}\right|
$$

where $\beta$ is an adjustable paraneter This is the density (ignoring normalization) of a hydrogenic is oflitit with the second term added to ensure that $\rho(r)$ decreases monotonically with $r$ over the whole rang. ..: possible interaction distance $\left(2^{9}\right.$ is the relative normalization factor for a 46 orbital with a dicubled exprum.⿲丿丨 , This was originally chosen for describing first-row transition metals, but has been found to work well fi,r is number of fec metals

Rose et al [9] have shown that the cohesive erergy of nosit metals can be scaled to simple umuruit? function. which is approximately

$$
E_{1}\left(a^{*}\right)=-E_{11}(1+a \cdot) e^{-a^{*}} \quad \therefore
$$

where $a^{*}$ is a reduced distance variahle and $E_{i}$ is the depth of the function at the munimum $i a^{*}=11$.

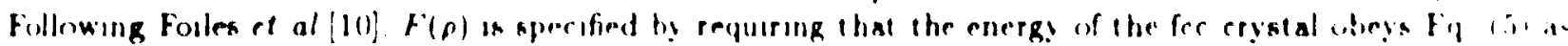

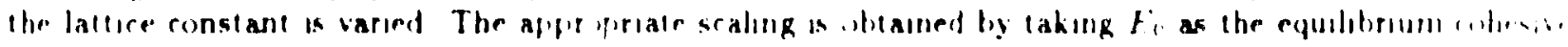
enregs of the solde (Ficen). and defining $a^{*}$ by

$$
a^{\bullet}=\left(a / a_{0}-11 /\left(r_{C \infty A} / 9 / B i 2\right)^{1 / 2}\right.
$$

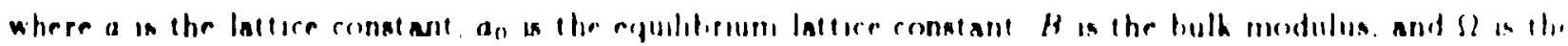

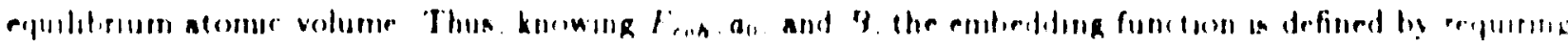

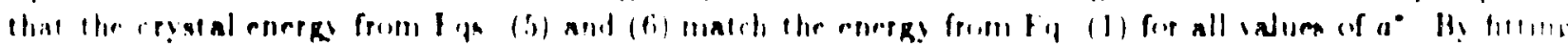

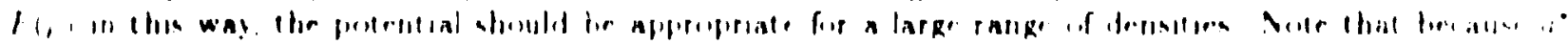

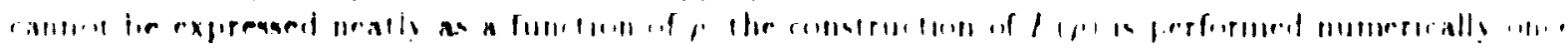
and ,

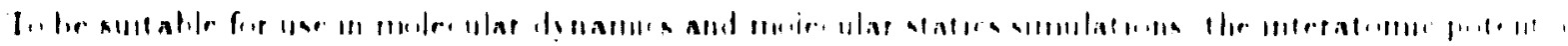

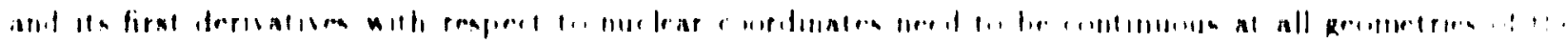

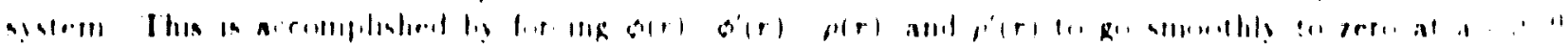

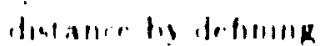

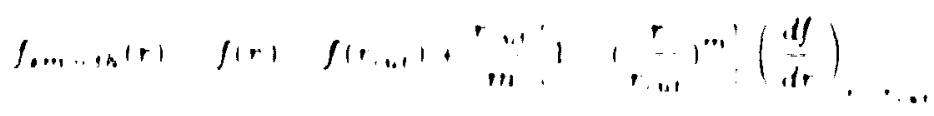

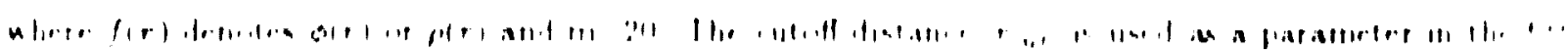

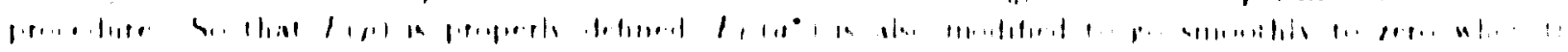

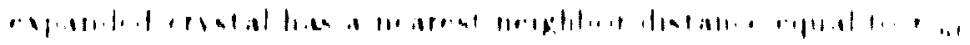


Having specified the functional forms for $o(r) \rho(r)$. and $F(p)$. we now describe the fitting prisedure Because of the way $F(\dot{\rho})$ is determined, the potential always gives a perfect fit to the experimental valur. $a_{0}, E_{\text {eah }}$. and $B$ for any choice of $\phi(r)$ and $\rho(r)$. The remaning five parameters, $R_{M}, D_{M}, a_{M}, 3, a_{1} r_{c L}$ are determined hy ninimizing the root-mean-square deviation $(1-m$,$) between calculated and expermintitial$ thermodynamic data. This is accumplished using a simplex procedure [11]

For $\mathrm{Ni}$ and $\mathrm{Al}$, he experimental data cousists of the thres cuhic elastic constants $\left(r_{11}, r_{12}\right.$, and $\left.r_{44}\right) l_{11}$ varaney formation energy $\left(\Delta E_{M}^{\prime}\right)$ and the bond length $\left(R_{e}\right)$ and bond 'nerg! $\left(D_{e}\right)$ of the diatomic me ierul. In addition, the search was constrained by the requirement that the fer erystal structure be more statile thiti. either bec or hes with ideal c/a ratio As can he seen in Ref 3, the fit is excellent for Ni ( $1 \mathrm{rm}$, = $11 . i$, and quite good for $A l(1 \mathrm{rma}=3857$ )

For $\mathbf{B}$ and $\mathbf{S}$. hecause experimental thermodynamic datn are lecs readily avalable and the native crystial forms are more complex. we employed a different approach Locai density band structuri caiculations wi re performed on $B$ and $S$ in hypothetical crystal structures using the linearized muffin tin orbital (LMIJ), method [12] The thermodynamic properties calculated using LMTO for three different crystal structure? (fec, bec, and fec with a periodic vacancy structure obtained by removing one of the four cubic sublatlires were then used in the parameiep searches The only experimental infoimation guiding the fits were the diatomic data for $B_{2}$ and $S_{2}$ These fits are shown in Table $I$.

TABLE I Beal fit is LMTO and expeimental data for B and S The values of ao, Eroh and $B$ for the fee phase match exactly due to the way $F(\bar{\rho})$ is determined

\begin{tabular}{|c|c|c|c|c|c|}
\hline \multirow[t]{2}{*}{ Source } & \multirow[t]{2}{*}{ Property } & \multicolumn{2}{|c|}{$\mathbf{B}$} & \multicolumn{2}{|c|}{$\mathbf{S}$} \\
\hline & & "F.xipl" & Cale & -Exp1" & Calc \\
\hline I.MT() & $\operatorname{foc} a(A)$ & 291 & & $41+3$ & \\
\hline LMTO & fer Exon $\left.(a)^{\prime}\right)$ & 5) 1.13 & & 218 & \\
\hline I.MT() & fcc $B\left(10^{13} \mathrm{erg} / \mathrm{cm}^{3}\right)$ & 202 & & 75.5 & \\
\hline I.MT() & lier on $(A)$ & 234 & 2.13 & 223 & 329 \\
\hline 1.117() & fore lienn $\left.(\cdot)^{*}\right)$ & 49.5 & 531 & 240 & $\because 18$ \\
\hline LMTO & $\operatorname{hec} B\left(10^{1} \operatorname{erg}^{\prime} / \mathrm{rm}^{3}\right)$ & 211 & 212 & 100 & 07.5 \\
\hline 1.910 & $3 / 4$ fre ar, $(A)$ & $27 k$ & $2 \mathrm{fis}$ & 397 & $3 ! 4$ \\
\hline I.MT() & $3 / 4$ fer tirnh $(+1)$ & 5in & stifi & $2(6)$ & 212 \\
\hline experimmut & diatromir $K, A_{1}$ & 18,1 & I li: & I $k ! !$ & I H.3 \\
\hline exprerimentil & diatimu, II, |rl' & $: 11:$ & $\therefore \mathrm{Mi}$ & 111 & 435 \\
\hline
\end{tabular}

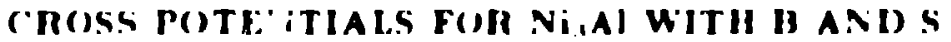

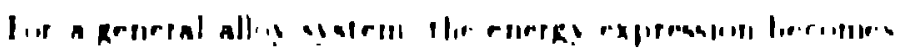

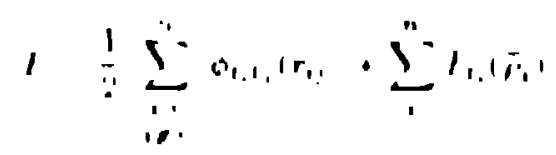

nli. te

$$
\overline{1} \quad \sum_{1}^{\prime \prime} \cdots \cdots !
$$




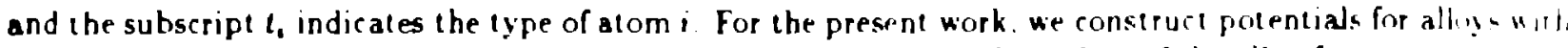

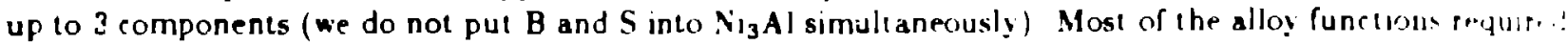

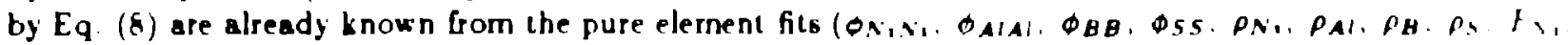
$\left.F_{A l}, F_{B}, F_{S}\right)$, leaving $\Phi_{N, A l}, \phi_{N i B}, \phi_{A l B}, \phi_{N i s}$, and $\Phi_{A I S}$ to be determined Just as for the pure elememiinese par functions are taken as Morse potentials. In addition to optimizing the pair potentials. thert ar. two othet types of variation that can be utilized to improve the fit to alloy properties Examination if $f \cdot ;$ (1) shows that the energy of a homonuclear system is invariant under two types of transformation. sialit. $\rho(r)$ and a 'ding a linear term to $F(\bar{\rho})$ For an atom of type $A$, the prsealing iransformation is

$$
\begin{aligned}
& \rho_{A}(r) \rightarrow s_{A} \rho_{A}(r) \\
& F_{A}[\bar{\rho}] \rightarrow F_{A}\left(\frac{\dot{s}}{B_{A}}\right)
\end{aligned}
$$

and the lineas embedding term transformation is given by

$$
\begin{gathered}
F_{A}[\rho]-f_{A}[\bar{\rho}]+g_{A} \rho \\
\varphi_{A A}(r)-\phi_{A A}(r)-2 g_{A} \rho_{A}(r)
\end{gathered}
$$

While these transformations do not affect the pure element energ they do affect the energy of an allin system We thus uee thear additional $g$ and s parmoters in op:imizing the fits to nllog properties fin ian $n$-component alloy. there are $n-1$ independent braling transiormations [F. $(10)]$ and $n$ independent linear term transformations [Eq (11)]

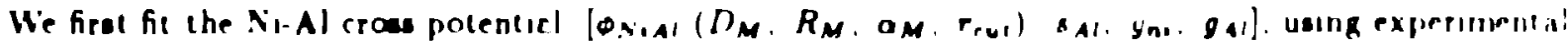
thermodynamic data on $V_{3} A l$ and $B 2$ phase $N i A l$ as shown in Ref 3 Special allention was requirel 1.

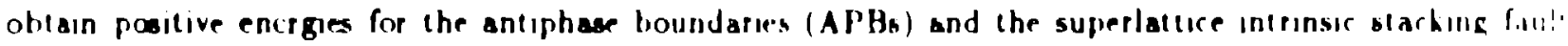
energies Since the time this fit was originally performed, new experimental values have been defertuill. :

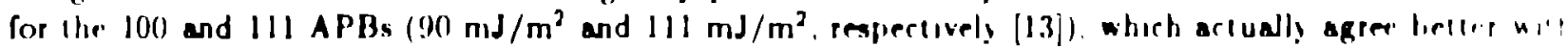

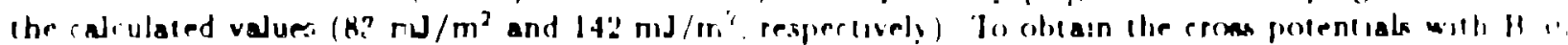

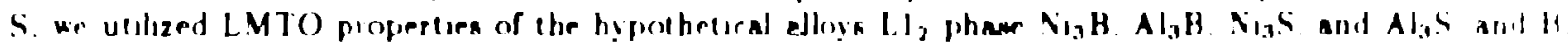

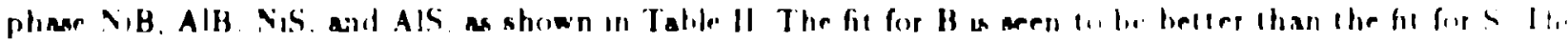

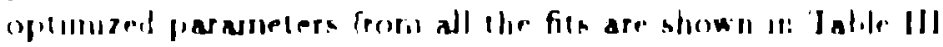

\begin{tabular}{|c|c|c|c|c|c|c|c|c|}
\hline \multirow[t]{2}{*}{ Priplert! } & \multicolumn{2}{|c|}{$\mathrm{Nill}$} & \multicolumn{2}{|c|}{ Al B } & \multicolumn{2}{|c|}{ vis } & \multicolumn{2}{|c|}{$1 ! 4$} \\
\hline & 1.1110 & ( nl & 1.1910 & Inl & 11111 & I al. & 1.11111 & 11 \\
\hline 1,$1 ; \Rightarrow A_{1}$ & $3: 314$ & $13: 4$ & $\mid 1 \times 1$ & $3: 19$ & $3 ; 14$ & is ifi & 119 & 1 \\
\hline $1: 1: 1 \ldots, 21)$ & $1 \mathrm{N1}$ & $4 \times 11$ & $3 \because$ & 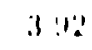 & $3 ! r$ & 4 in & 3 sid & . $\cdot$ \\
\hline 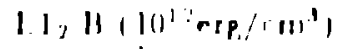 & 2 sei & $\because$ in & 116.1 & $11 \%$ & 211 & 315 & 114.1 & $i$ \\
\hline$H: A, A_{1}$ & 2 is & $25 x$ & 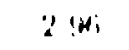 & $2 m i$ & $2 \cdots$ & $2 ! n$ & 112 & 1,1 \\
\hline $1121 \ldots$ no 101 & $5: 111$ & $5: 31$ & $1: 1$ & $1 \%$ & $3: 11$ & $17 \%$ & $.1 ! 11$ &. \\
\hline
\end{tabular}

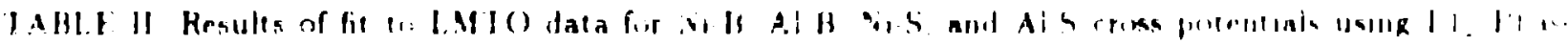

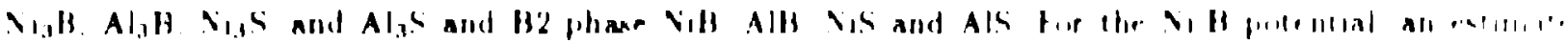

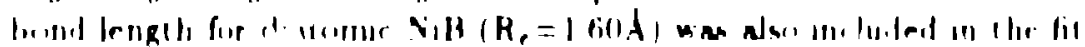




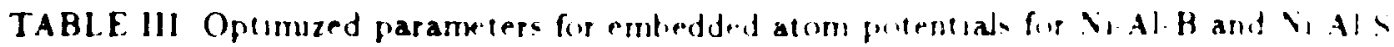

\begin{tabular}{|c|c|c|c|c|c|c|c|}
\hline & $\begin{array}{l}D_{M} \\
(+1)\end{array}$ & $\begin{array}{l}R_{M} \\
(A) \\
\end{array}$ & $\begin{array}{l}a_{i-1} \\
\left(A^{-1}\right)\end{array}$ & $\left(A^{-1}\right)$ & $\begin{array}{l}\text { rut } \\
(A)\end{array}$ & (A) & $\left.(e)^{8} A^{3}\right)$ \\
\hline$N_{1}$ & 15335 & 22053 & $17 \% 2 x$ & $36.40 \mathrm{~m}$ & $4-2 \times 45$ & $100(00)$ & 65145 \\
\hline Al & 3Titio & 21176 & $14 x i 4$ & $3.323:$ & 5.55501 & 0 oil:23 & -0220511 \\
\hline B & $0-1182$ & 16517 & $3 j 915$ & $20111 \%$ & $43 \pi 16$ & $(19 k 134936$ & - O ORRTAi \\
\hline$\$$ & 05976 & (1) 2495 & 20445 & $+70,3:$ & $5(184)$ & $11000+1$ & $210.5 \mathrm{k}$ \\
\hline 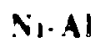 & 30322 & $20 \times 406$ & 1030 & & 54634 & & \\
\hline$N_{1}-\mathrm{B}$ & $02 \times 22$ & 23149 & 2 4x:? & & $2 \times 1 \times 1$ & & \\
\hline AI. B & 01295 & 2 REIC & i 39014 & & 3 onin: & & \\
\hline$N_{1}-S$ & $094 i 9$ & 24448 & $29-7 \times 4$ & & $A(13 \times: 2$ & & \\
\hline AI.S & 07422 & 21196 & 11294 & & $5262 \%$ & & \\
\hline
\end{tabular}

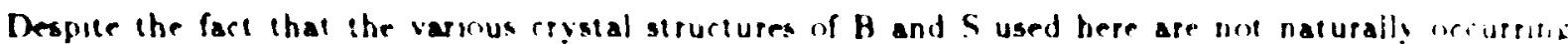
forms potentials that give a reasonatile descriplion of these higher energ structures are pertiaps as mel. suited to the tak at hand that of describing $B$ and $S$ as minority alloy constituents at $N_{13} A \mid(; B$, is potentials that are fit to the most stable structures Twi possitily more important questions ar. ial $f_{1}$ in accurate are the LMTO resules to which the potentials ase fit and (b) hou well can the emitiedded atint. mettod be expected io do in drecribing systems contaning $B$ and $S$ Regarding question 1 al. we note thit. using the same LMTO method to calculate thermodynamic data for the known crystads $M i$ Al and $V_{i}, i$ leads to deviations from experiment of at mowt $10 \%$ and often siguificantly laxs We thus feel that usulig 1 !.

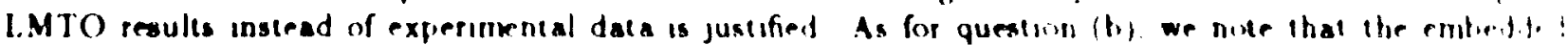

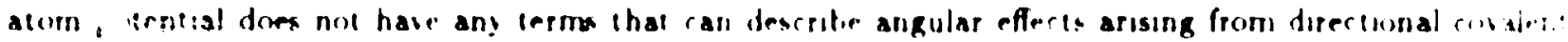

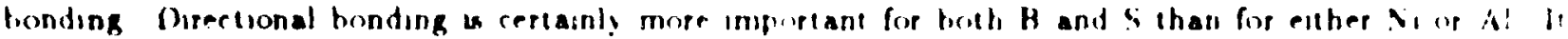

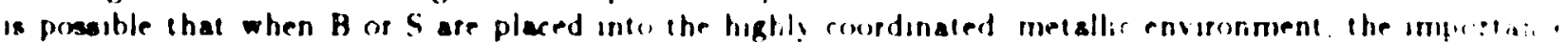

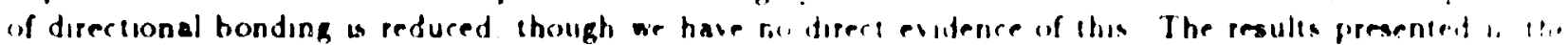

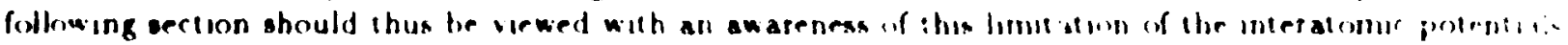

\section{GRAIN BOLNDARY SIMULATIONS}

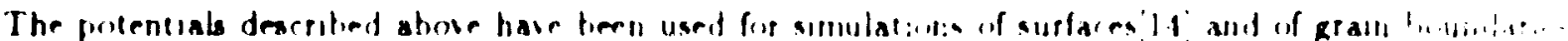

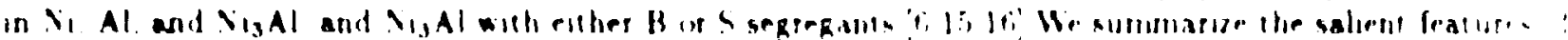

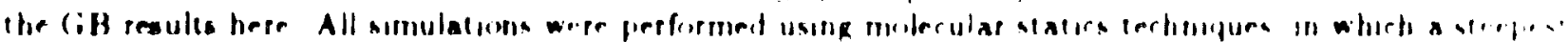

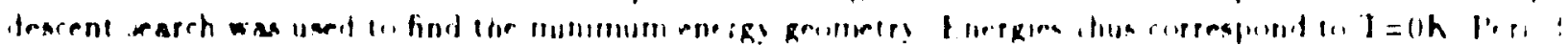

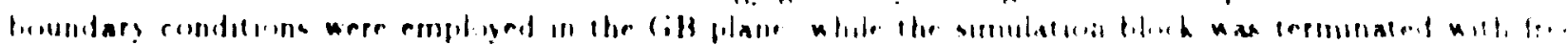

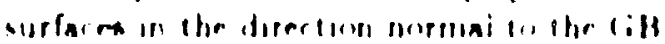

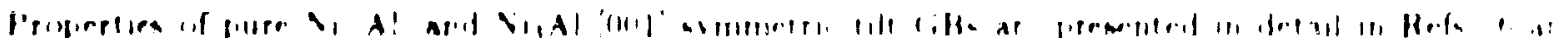

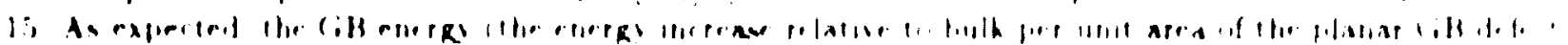

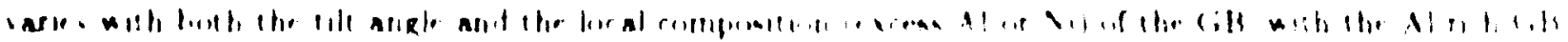

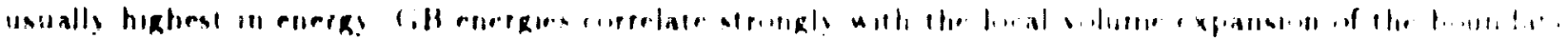

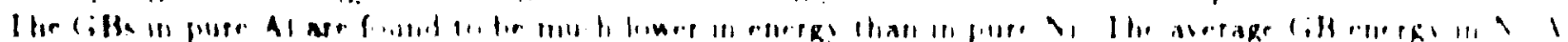

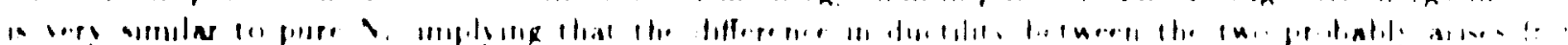

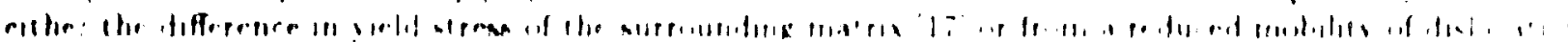

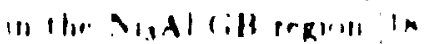

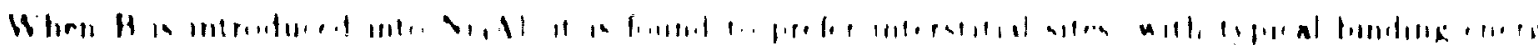

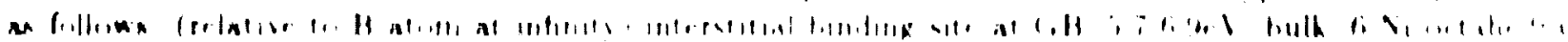

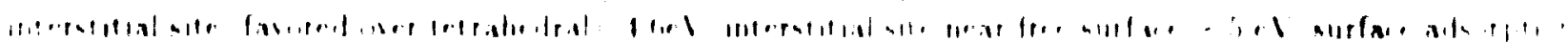

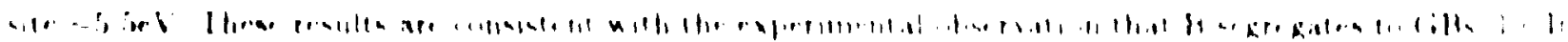




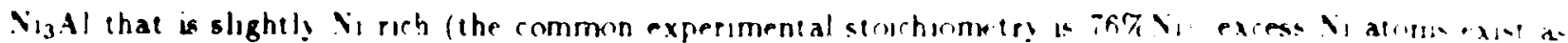

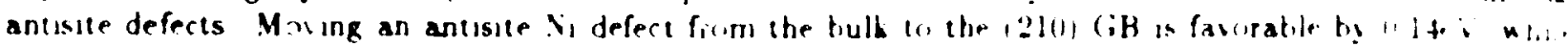

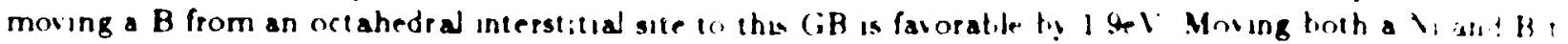

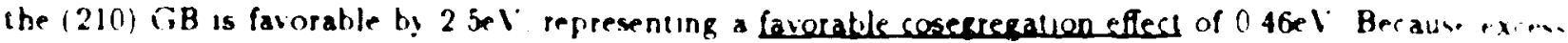

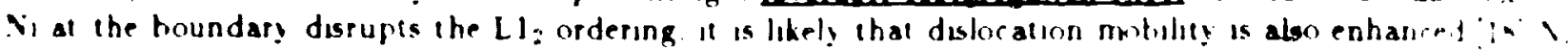
cosegregation may thus be an important component of the B ductilizing effert

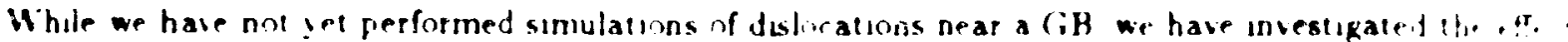
of $\mathrm{B}$ on the boundary cohesion This was done in a simple fashon by fulling afiant the optimiz..: lit:

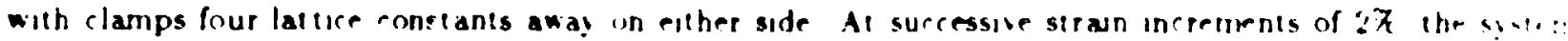
was allowed in relax to the lowest possitile energ With this approach thr system may not hreat at it. same position or in the same was a il would in a slow!y strained thermalized systemi hut the resul: a: qualitatwely instructwe nonetheless The resuling stress-stran eurves are shown in fig 1 for th. 1,1 (210, GB with segregated $S_{1}$ and of $B$ imore desal can be found in Refs 16 and 201 , (.ote that t...: the stres and the stian are much largep than ispiesl experimental values for a macrobentur stress-atrait curve This us because the present simulations give local GB properties) The additinn of $B$ and $X_{i}$ is w...t. to significantly enhance both the maximum stress the GB can accommodate and the total work dene ill th. GH igiven by the area under the strear strain curve) before falute In this case $B$ alone has inly a smis:

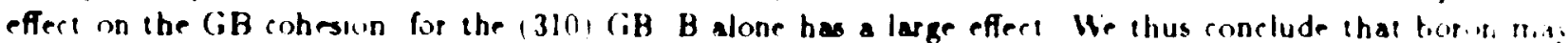

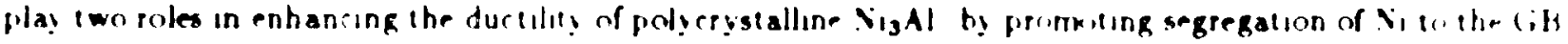
it disrupts the local order and increases the enhesive strength of the (;H

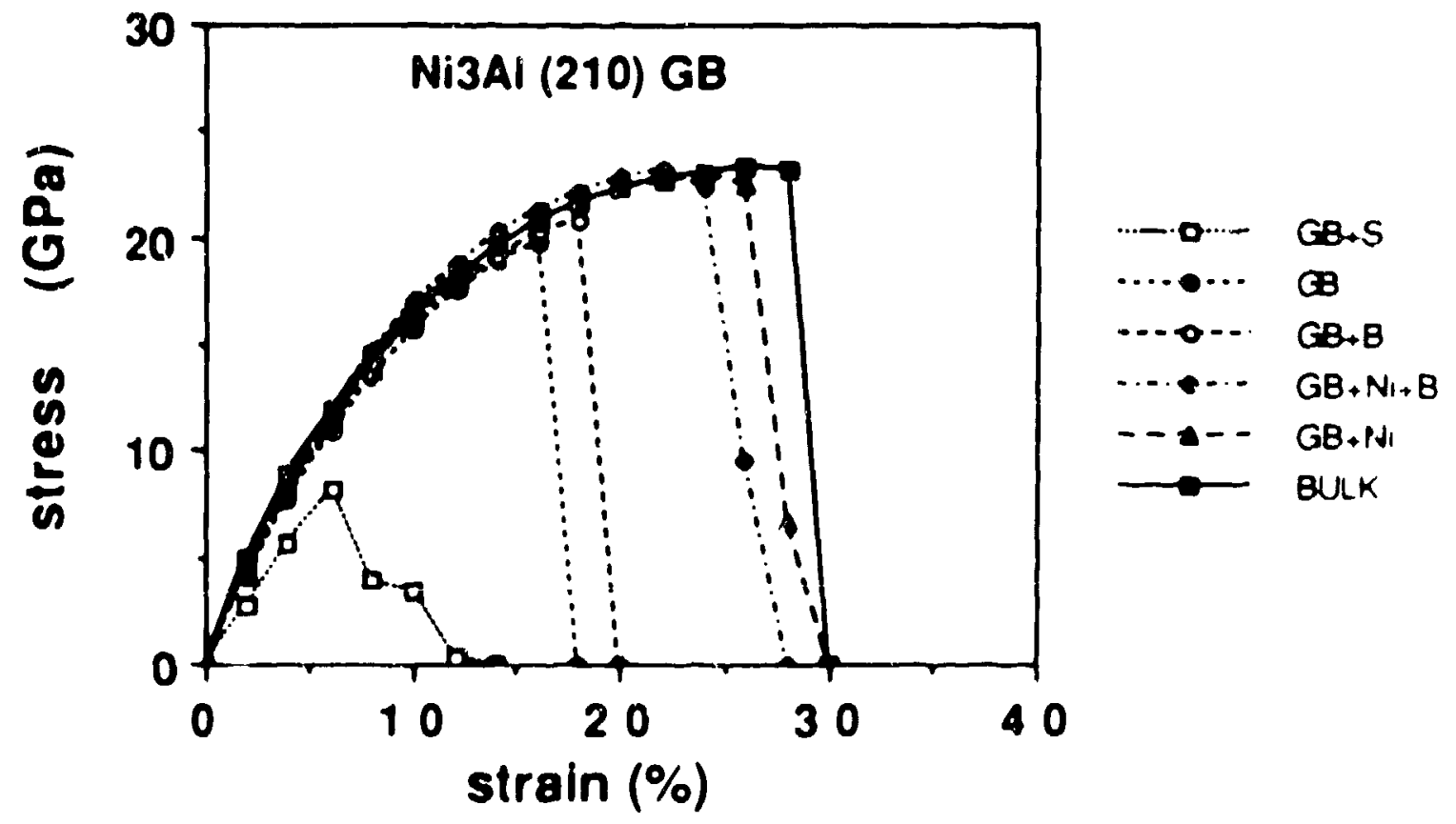

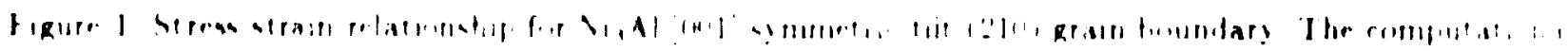

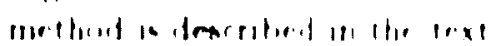

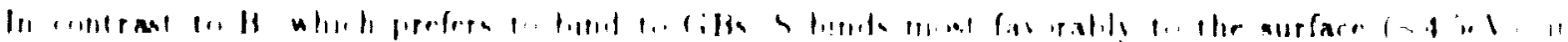

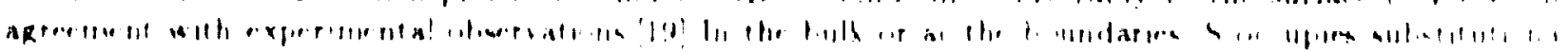

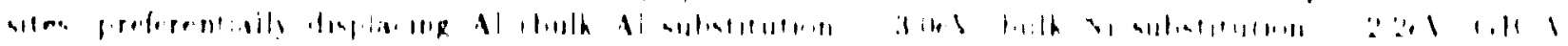




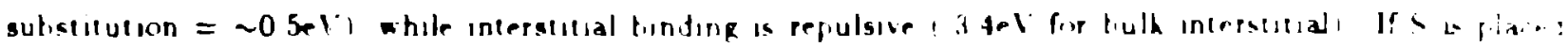

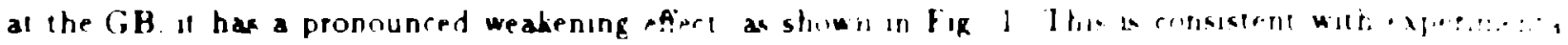
obsersations of sulfur entiritlement in sener material ' $:$ ?"

\section{REFERENCES}

I C T Liu C L White and J A Hopton Acla Metall 33213 ilga;,

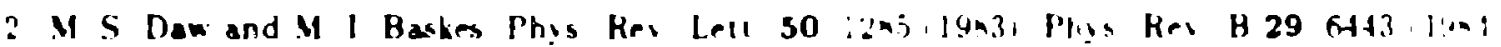

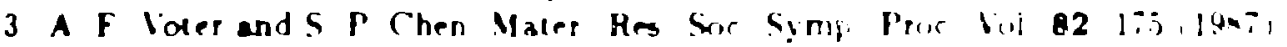

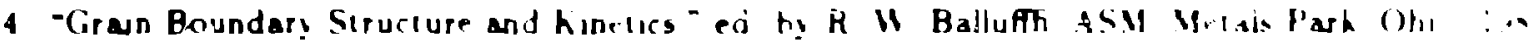

5 A P Siftion. Int Metals Res (1984) $293 i$

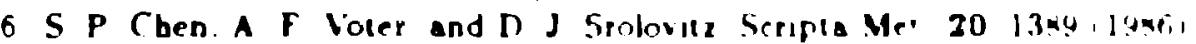

i S M Forles MRS Proceeding 81 il 1 195:

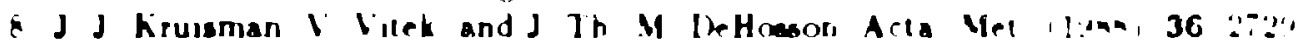

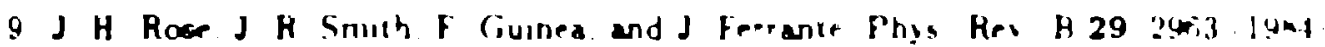

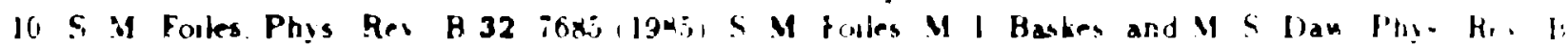
33 . 2983 (19/6)

1) J A Nelder and $R$ Mead romp J 7 30\% (196.j.

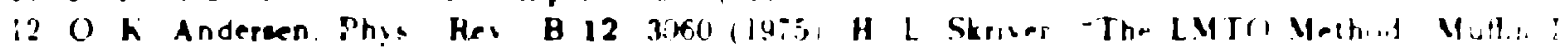

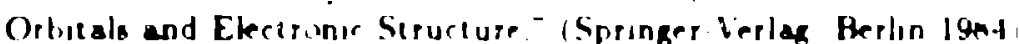

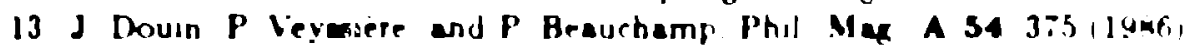

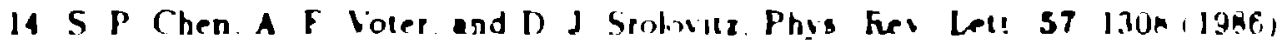

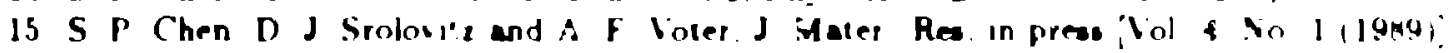

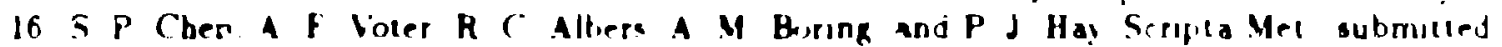

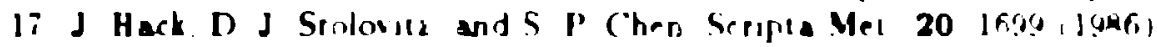

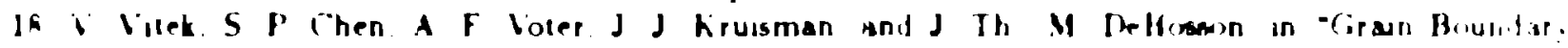

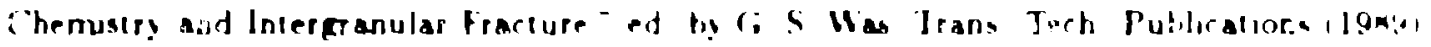

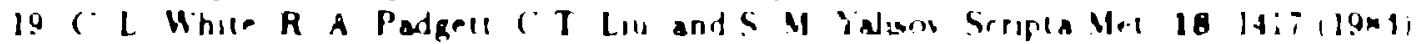

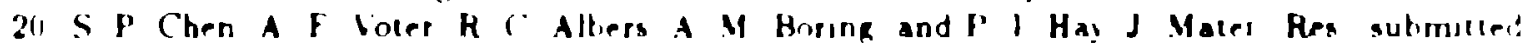

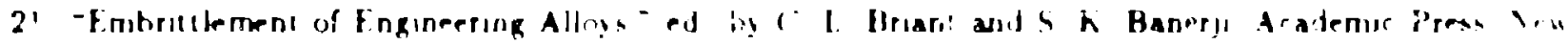
fork NY IU⿴囗十) 